ISSN 1991- 8690

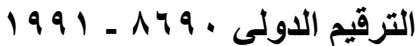

website : http:// jsci.utq.edu.iq

Email: utjsci@utq.edu.iq

\title{
Electrical energy generation from nanowire structures
}

\author{
R. R. Attab \\ C. A. Emshary \\ Physics Department-College of Education for Pure Science- Basrah University
}

\begin{abstract}
This work numerically estimate the amount of electric voltage generation from Zing oxide, Barium titanium, Gallium nitride, Lead zirconate titanate $\left(\mathrm{ZnO}, \mathrm{BaTiO}_{3}, \mathrm{GaN}\right.$ and $\left.\mathrm{PZT}\right)$ nanowire structure respectively and other hetro-structure or doped structure like $(\mathrm{ZnMgO}, \mathrm{GaAlN})$ having rectangular and circular cross sections with dimension of length and width $(l, b) 600,50$ nanometers. The amount of the generated voltage seem enough to power biosensor, nanosensor, or even biomedical device. The effect of nanowire length, width and temperature and the effect of applied force are studied, All theses parameters having profound effect on the amount of the maximum generated voltage.
\end{abstract}

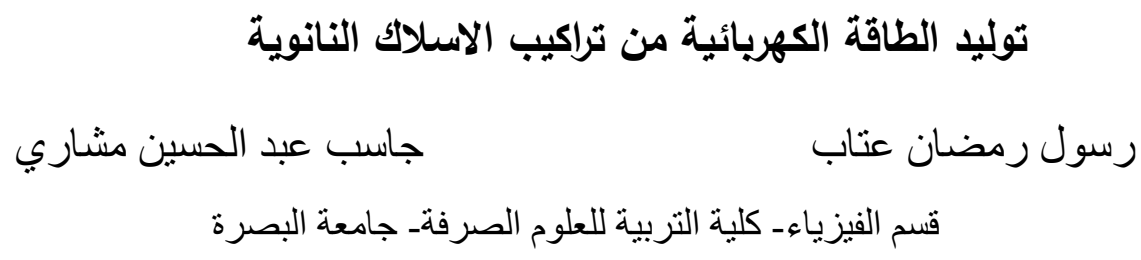

الخلاصة

في هذا العمل نم تقدير كمية الفولتية الكهربائية المستحصلة من المواد ZnO, BaTiO 3 , GaN ) (PZT, ZnMgO, GaAIN عددياً والتي تكون على شكل تراكيب اسلاك نانوية ذات مقاطع مستطيلة ودائرية. ان مقدار الفولتية المنولدة كافية لتتغيل اجهزة ذات قدرة قليلة كأن تكون على شكل متحسسات

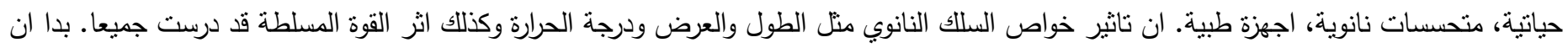
لكافة المعاملات المذكورة اثر واضح في مقدار الفولتية العظمى المنولدة.

\section{Introduction}

With the threatening of global warming and energy crises, searching for renewable and green energy resources is one of the most urgent challenges to sustainable development of human civilization. At the large-scale, besides the well known energy resources that powered the world today, such as petroleum, coal, hydraulic, natural gas and nuclear, active research and development are being taken in exploring alternative energy resources such as solar, geothermal, biomass, nuclear, wind, and hydrogen. At a much smaller scale, energy and technologies are desperately needed for independent, sustainable, maintain-free and continuous operations of implantable biosensors, ultrasensitive chemical and bio-molecular sensors, nano-robot, micro- electromechanical systems, remote and mobile environmental sensors, homeland security and even portable wearable personal electronics [1-3]. Building self-power nanosystems is a future direction of nanotechnology [4]. A nanosystem is an integration of nanodevices, functional components, and a power source. Energy harvesting from the environment for powering a nanosystem is vitally important for its independent, wireless and sustainable operation [5]. A piezoelectric nanogenerator (NG) is a promising approach for this application. The NG is based on a vertically aligned $\mathrm{ZnO}$ (for example) nanowire (NW) array that is placed beneath a zigzag electrode with a small gap [6]. The NG relies on the piezoelectric potential created in a nanowire once subjected to elastic straining, which drives the flow of charge carriers [7]. 
The zigzag electrode acts as an array of parallel integrated tips for simultaneously creating, collecting and outputting electricity from all of the active NWs. In this paper we present the results of calculating the maximum harvested voltage from Zing oxide, Barium titanium, Gallium nitride, Lead zirconate titanate $(\mathrm{ZnO}$, BaTiO3, GaN and PZT) nanowire structure respectively and other hetro-structure or doped structure like $(\mathrm{ZnMgO}, \mathrm{GaAlN})$ in the form of nanowires of two different cross-sections viz rectangular and circular as functions of NW length, width, temperature and applied force.

\section{Basic model}

To derive a theoretical expression for the harvested voltage from a NW, for a dielectric and piezoelectric material system, when the material is placed in an electric field and subjected to an external force Fy, the constitutive equations are[7]:

$$
\begin{aligned}
& \sigma_{i j}=c_{i j k l} \epsilon_{k l}-e_{i j k} E_{k}-\alpha_{i j} \Delta t \\
& D_{i=e_{i j k}} \epsilon_{i k}+\varepsilon_{i j} E_{i}+p_{i} \Delta t
\end{aligned}
$$

Here, the mechanical stress tensor $\sigma \mathrm{ij}$ and mechanical strain tensor $\epsilon_{\mathrm{ik}}$, The dielectric displacement Di and the electric field Ei and the temperature change $\Delta t, \mathrm{e}_{\mathrm{ijk}}$ , $\varepsilon_{\mathrm{ij}}, \mathrm{c}_{\mathrm{ijkl}}$ are the linear piezoelectric coefficient, dielectric constant and elastic constant respectively. $\alpha_{i j}, p_{i}$ are the thermoelastic and pyroelectric coefficients respectively.

\section{1- Rectangular NW structure}

When a lateral force Fy is applied at the free end of the NW and parallel to y-direction (see Figure1), normal stress ozz and shear stress components $\sigma \mathrm{Xz}$ and $\sigma y z$ appeared on the cross section along the $z$ direction, while other three components $\sigma \mathrm{zz}, \sigma \mathrm{Xz}$ and $\sigma y z$ are zero. Based on the saint- venant cantilever bending theory for a rectangular beam [8], one can calculate mathematical expression for $\sigma \mathrm{zz}$, $\sigma x y$ and $\sigma x z$ [8]. By the same way one can find expression for the strain components and the electric displacement. When a constant external voltage $\mathrm{v}_{\mathrm{y}}$ is applied on the NW along the y-direction and a uniform electric field $E_{y}=\frac{v_{y}}{b}$ will be induced inside the nanowire, and for a general case that both Fy and $\mathrm{v}_{\mathrm{y}}$ present.

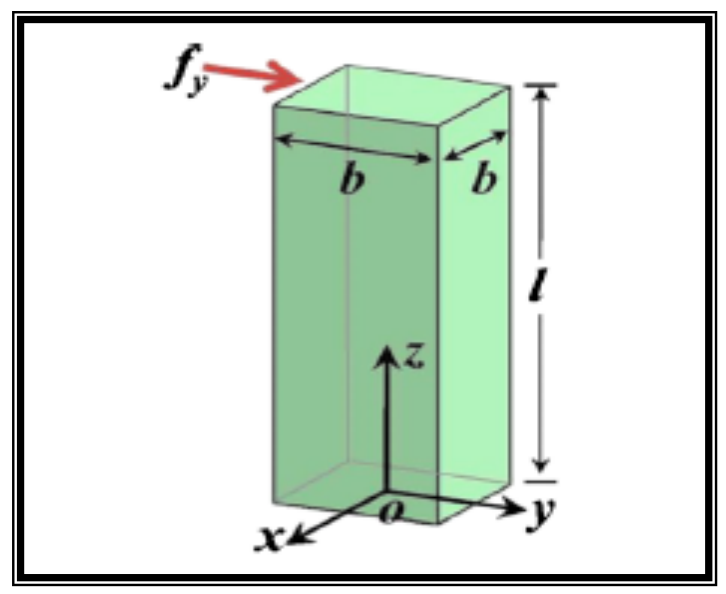

Figure (1): The rectangular cross section nanowire with external force $\mathrm{F}_{\mathrm{y}}$ [9].

To find out the total or maximum harvested voltage one can write down a general expression for the total energy stored in the NW ( $U_{\text {tot }}($ volt $\left.)\right)$. The total charge $Q_{\text {tot }}$ on the two side surfaces of the NW can be written as[10]:

$$
\begin{gathered}
Q_{\text {tot }}=\frac{\partial \mathrm{U}_{\text {tot }}}{\partial \mathrm{v}_{\mathrm{y}}} \\
Q=\left[\frac{F_{y}(1+v) \varepsilon_{\ell_{1}} b^{b^{3}}}{96 E I_{x x}}+2\left(\frac{(1+v)}{2 E} \theta_{15}{ }^{2}+\frac{1}{4} k_{11}\right) b_{y}\right]-\left(\frac{(1+v) e_{15}}{2 E} a_{x z} \Delta t-\frac{1}{4} p_{x z} \Delta t\right) b l
\end{gathered}
$$

where $\mathrm{E}$ - young modulus, $v$ - poisson ratio, $I_{x x}$ moment of inertia, $\alpha_{x z}, p_{x z}$ are the thermoelastic coefficient and pyroelectric coefficient respectively. $e_{15}, \mathrm{k}_{11}$ are piezoelectric and dielectric constants. Hence the NWs capacitance $\mathrm{C}_{\mathrm{p}}$ along the $\mathrm{y}$ direction is:

$$
\mathrm{C}_{\mathrm{p}}=\frac{\partial \mathrm{Q}}{\partial \mathrm{v}_{\mathrm{y}}}=2\left[\frac{(1+v)}{2 E} e_{15}^{2}+\frac{1}{4} k_{11}\right] l
$$

The total harvested voltage $\Delta v_{\max }$ is:

$$
\Delta v_{\max }=\frac{\left[\frac{F_{y}(1+v) e_{15} l b^{3}}{96 E I_{x x}}+2\left(\frac{(1+v)}{2 E} e_{15}{ }^{2}+\frac{1}{4} k_{11}\right) b v_{y}\right]-\left(\frac{(1+v) e_{e_{15}}}{2 E} a_{x z} \Delta t-\frac{1}{4} P_{x z} \Delta t\right) b l}{2\left[\frac{(1+v)}{2 E} \varepsilon_{15}^{2}+\frac{1}{4} k_{11}\right] l}(6)
$$

Here the term that associated with temperature variance $(\Delta t)$ is:

$$
\left(\frac{(1+v) e_{15}}{E} \alpha_{x z} \Delta t-\frac{1}{2} p_{x z} \Delta t\right)
$$


In many applications for piezoelectric NW generators no applied voltage is present and the NW is considered as an open circuit system thus eq.(6) can be reduced to :

$$
\Delta v_{\max }=\frac{\left[\frac{\mathrm{F}_{\mathrm{Y}}(1+v) e_{15} b^{3}}{96 E I_{x x}}\right]-\left(\frac{(1+v) e_{15}}{E} \alpha_{x z} \Delta t-\frac{1}{4} p_{x z} \Delta t\right) b}{\left[\frac{1}{G} e_{15}^{2}+\frac{1}{2} k_{11}\right]}
$$

Where $\mathrm{G}$ - shear modulus.

\section{2- Circular NW structure}

Based on the figure (2) one can arrive at the final expression for the maximum harvested voltage for the circular NW:

$$
\Delta v_{\max }=\frac{\left[\left(\frac{3}{4}+\frac{v}{2}\right) \frac{\mathrm{F}_{\mathrm{y}} e_{15} l r^{3}}{12 E I_{x x}}\right]+\left(\frac{(1+v) e_{15}}{E} \alpha_{x z} \Delta t-\frac{1}{2} p_{x z} \Delta t\right) r l}{2\left[\frac{(1+v)}{E} e_{15}^{2}+\frac{1}{2} k_{11}\right] l}
$$

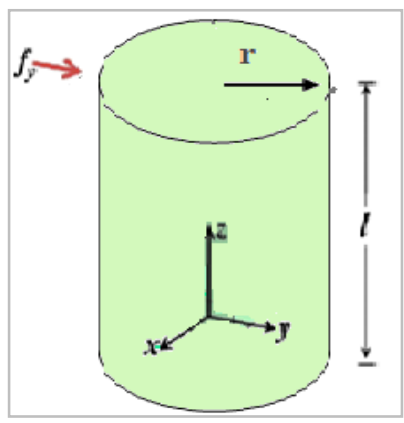

Figure (2): The circular cross section nanowire with external force[11].

\section{Results and discussion}

The maximum harvested voltage from nanowire dependence on length, width temperature and applied force. Relations are found using the equations (6) and (7) for the rectangular and circular NW for the different materials (ZnO, PZT, BaTiO3, ZNMgO, GaAlN and $\mathrm{GaN})$. The pyroelectric and thermoelastic coefficients for the studied materials are given in tables 1-3. Figures (3) and (4) shows the relation between maximum voltage harvested from the NWs for both rectangular and circular shapes for the different materials, against applied force. The relations show direct proportionality of $\Delta v_{\max }$ (voltage) vs Fy (Newton). Figures (5) and (6) show the relation between $\Delta v_{\max }$ against NW length for both the rectangular and circular shapes. No clear effect of the NW length on the maximum harvested voltage.
Table (1) Pyroelectric and thermoelastic coefficients for studied materials.

\begin{tabular}{|c|c|c|c|c|}
\hline Material & Symbol & $\begin{array}{c}\text { Pyroelectric coefficient } \\
{ }^{*} 10^{-6} \mathrm{C} / \mathrm{m}^{2} \mathrm{~K}\end{array}$ & $\begin{array}{c}\text { Thermal expansion } \\
\text { coefficient }{ }^{*} 10^{-6} 1 / \mathrm{mK}\end{array}$ & Reference \\
\hline $\begin{array}{c}\text { Lead zirconate } \\
\text { titanate }\end{array}$ & $\mathrm{PbZrTiO}_{3}$ & 238 & 6.6 & 12,13 \\
\hline Barium titanium & $\mathrm{BaTiO}_{3}$ & 200 & 3.8 & 14 \\
\hline Gallium nitride & $\mathrm{GaN}$ & 29 & 3.34 & 15,16 \\
\hline Zing oxide & $\mathrm{ZnO}$ & 57 & 4.7 & 17 \\
\hline Hetrostruc-ture & $\mathrm{GaAlN}$ & 121 & 5.59 & 17 \\
\hline Hetrostruc-ture & $\mathrm{ZnMgO}$ & 43 & 13.6 & 17 \\
\hline
\end{tabular}

Table (2) Compliance parameters and dielectric coefficient for studied materials.

\begin{tabular}{|c|c|c|c|c|c|c|c|}
\hline Material & $\mathrm{K} 11$ & $\mathrm{C}_{11}{ }^{*} 10^{9}$ & $\mathrm{C}_{12}{ }^{*} 10^{9}$ & $\mathrm{C}_{13}{ }^{*} 10^{9}$ & $\mathrm{C}_{33}{ }^{*} 10^{9}$ & $\mathrm{C}_{44}{ }^{*} 10^{9}$ & Reference \\
\hline $\mathrm{PZT}$ & 1800 & 126 & 79.5 & 84.1 & 117 & 23 & 18,19 \\
\hline $\mathrm{BaTiO}_{3}$ & 4400 & 22.2 & 13.4 & 6.1 & 24 & 43 & 18,20 \\
\hline $\mathrm{GaN}$ & 9.28 & 296 & 130 & 120 & 395 & 241 & 17,20 \\
\hline $\mathrm{ZnO}$ & 7.77 & 207 & 117.7 & 106.1 & 209.5 & 44.8 & 17 \\
\hline $\mathrm{GaAlN}$ & 8.5 & 367 & 135 & 103 & 405 & 95 & 17 \\
\hline $\mathrm{ZnMg} 0$ & 6.6 & 396 & 137 & 108 & 373 & 116 & 17 \\
\hline
\end{tabular}

\begin{tabular}{|c|c|c|c|c|}
\hline Material & $\mathrm{e}_{15} \mathrm{C} / \mathrm{m}^{2}$ & $\mathrm{e}_{31} \mathrm{C} / \mathrm{m}^{2}$ & $\mathrm{e}_{33} \mathrm{C} / \mathrm{m}^{2}$ & Reference \\
\hline $\mathrm{PZT}$ & -0.977 & -1.8 & 9.05 & 21 \\
\hline $\mathrm{BaTiO}_{3}$ & -0.56 & -0.7 & 6.7 & 20 \\
\hline $\mathrm{GaN}$ & -0.48 & -0.6 & 1.46 & 15 \\
\hline $\mathrm{ZnO}$ & -0.45 & -0.51 & 1.22 & 17 \\
\hline $\mathrm{GaAlN}$ & -0.30 & -0.49 & 0.73 & 17 \\
\hline $\mathrm{ZnMgO}$ & -0.37 & -0.62 & 0.69 & 17 \\
\hline
\end{tabular}

The relations between the maximum harvested voltage and NW width are shown in Figures (7) and (8) for the two different shapes. An indirect proportionality appears i.e the increase in width leads to the reduction of $\Delta v_{\max }$. The temperature dependence of $\Delta v_{\max }$ can be seen in figure (9) for the rectangular cross section and Figure (10) for circular one. Direct comparison between $\Delta v_{\max }$ against $\mathrm{F}_{\mathrm{y}}$ for both section in $\mathrm{ZnO} \mathrm{NW}$ is shown in figure (11) while the depends of $\Delta v_{\max }$ in $\mathrm{ZnO}$ for the rectangular cross section $\mathrm{NW}$ on applied force, $\mathrm{F}_{\mathrm{y}}$, length, width and temperature are shown respectively in figures (12), (13), (14) and (15). 


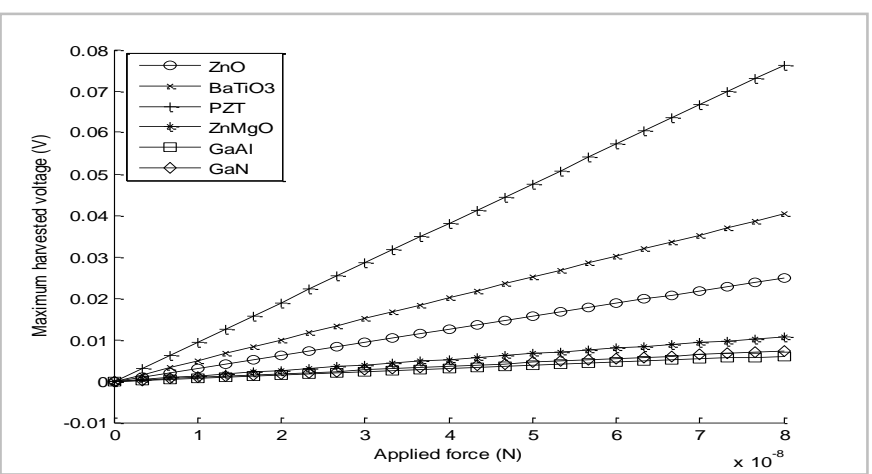

Figure(3): The maximum harvested voltage from $\mathrm{ZnO}$, $\mathrm{BaTiO}_{3}, \mathrm{GaN}, \mathrm{PZT}, \mathrm{ZnMgO}$ and $\mathrm{GaAlN}$ for rectangular cross section for variance nanowires against applied force.

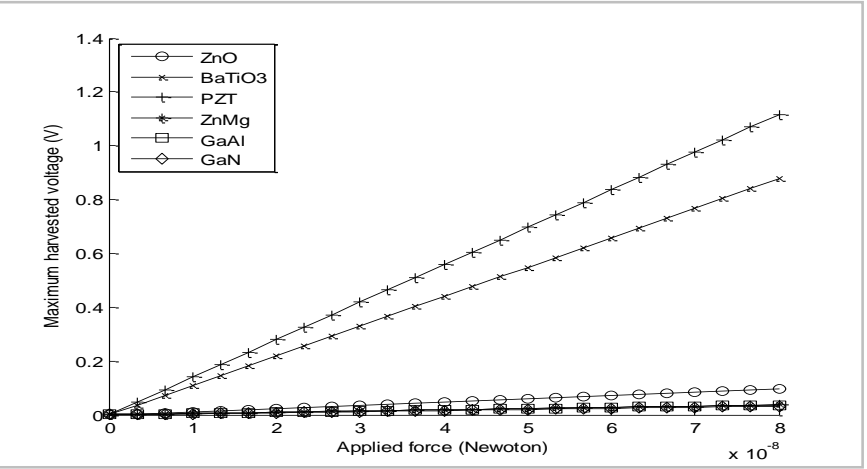

Figure (4): The maximum harvested from $\mathrm{ZnO}, \mathrm{BaTiO}_{3}$, $\mathrm{GaN}, \mathrm{PZT}, \mathrm{ZnMgO}$ and $\mathrm{GaAlN}$ voltage for circular cross section against applied force.

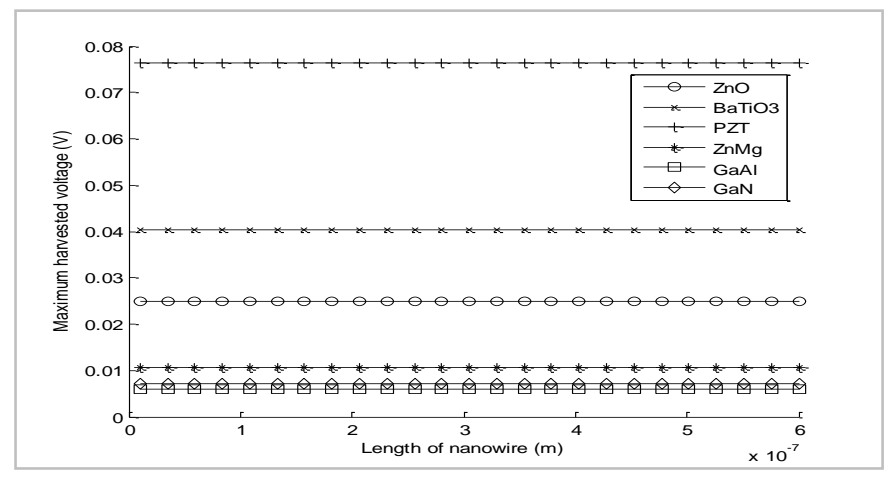

Figure (5): The maximum harvested voltage from $\mathrm{ZnO}$, $\mathrm{BaTiO}_{3}, \mathrm{GaN}, \mathrm{PZT}, \mathrm{ZnMgO}$ and GaAlN for rectangular cross section against length of nanowire.

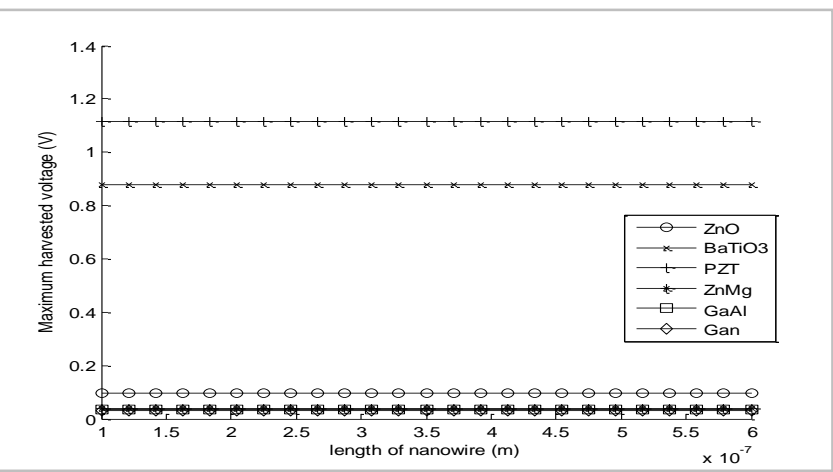

Figure(6): The maximum harvested voltage from $\mathrm{ZnO}$,

$\mathrm{BaTiO}_{3}, \mathrm{GaN}, \mathrm{PZT}, \mathrm{ZnMgO}$ and GaAlN for circular cross section with length of nanowire.

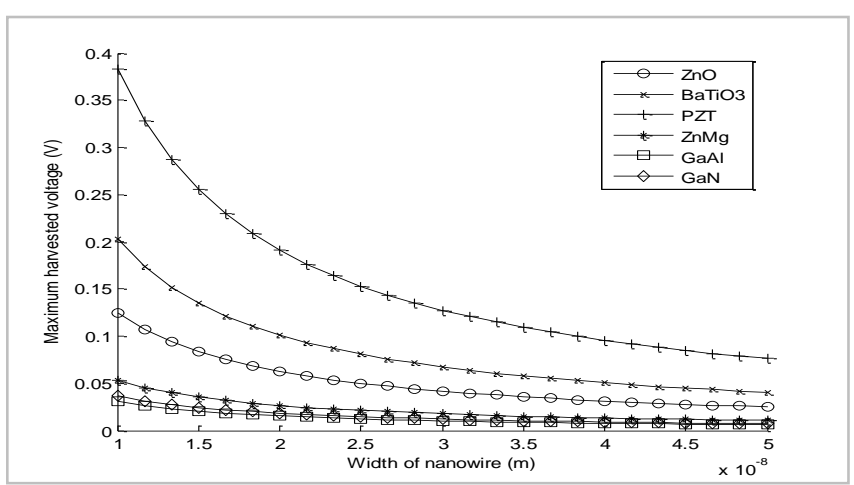

Figure (7): The maximum harvested voltage from $\mathrm{ZnO}$, $\mathrm{BaTiO}_{3}, \mathrm{GaN}, \mathrm{PZT}, \mathrm{ZnMgO}$ and GaAlN for rectangular cross section against width of nanowire.

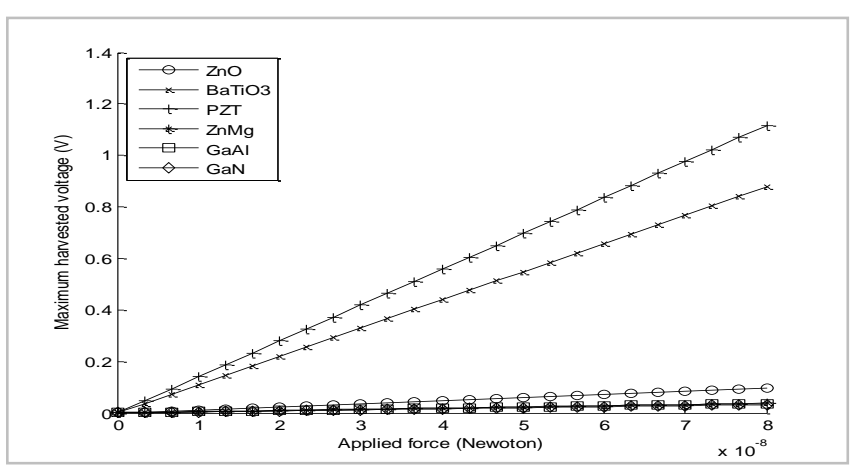

Figure (8): The maximum harvested voltage from $\mathrm{ZnO}$, $\mathrm{BaTiO}_{3}, \mathrm{GaN}, \mathrm{PZT}, \mathrm{ZnMgO}$ and GaAlN for circular cross section against applied force variance. 


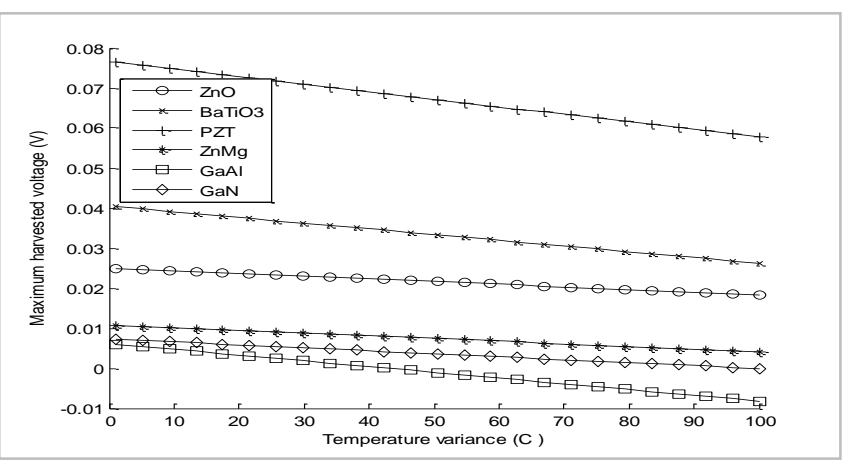

Figure (9): The maximum harvested voltage from $\mathrm{ZnO}$, $\mathrm{BaTiO}_{3}, \mathrm{GaN}, \mathrm{PZT}, \mathrm{ZnMgO}$ and GaAlN for rectangular cross section against temperature variance.

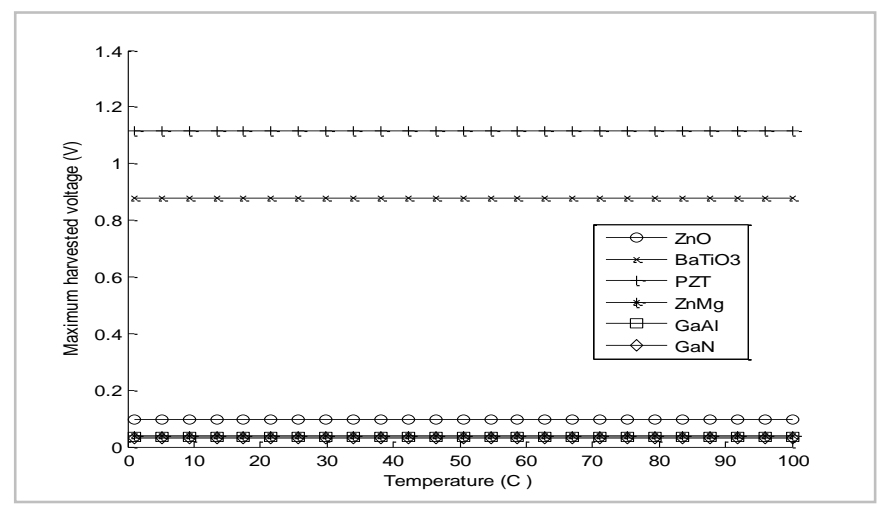

Figure (10): The maximum harvested voltage from $\mathrm{ZnO}, \mathrm{BaTiO}_{3}, \mathrm{GaN}, \mathrm{PZT}, \mathrm{ZnMgO}$ and $\mathrm{GaAlN}$ for circular cross section against temperature variance.

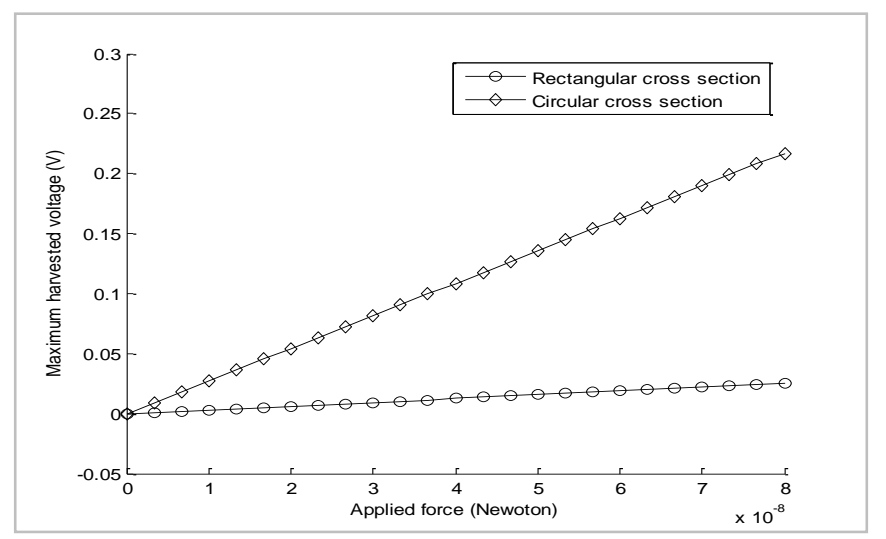

Figure (11): The maximum harvested voltage for rectangular and circular cross section of $\mathrm{ZnO}$ nanowire against applied force.

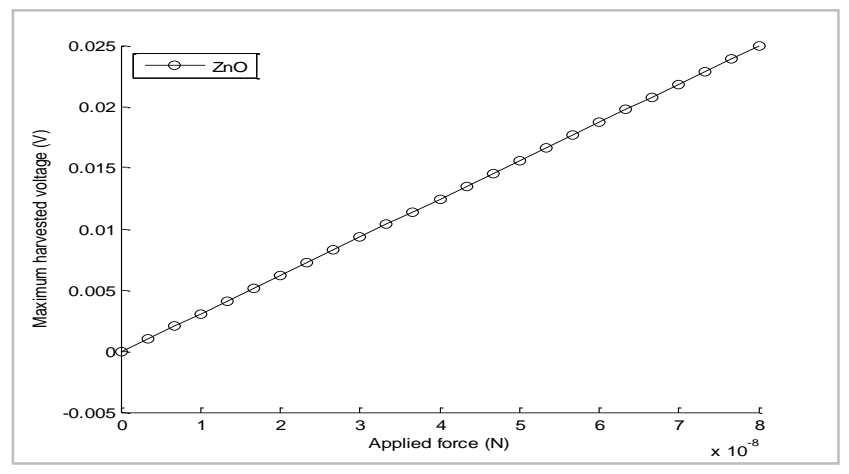

Figure (12): The maximum harvested voltage for rectangular cross section of $\mathrm{ZnO}$ nanowire against applied force.

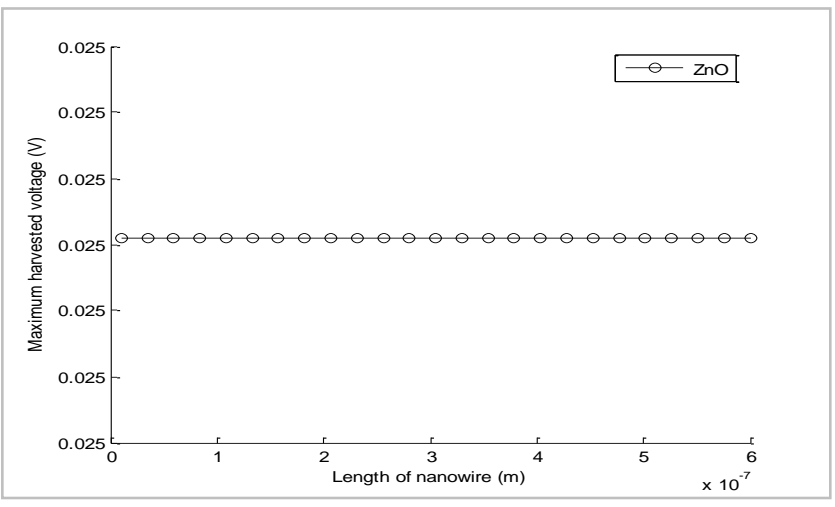

Figure (13): The maximum harvested voltage for rectangular cross section of $\mathrm{ZnO}$ nanowire against length of nanowire.

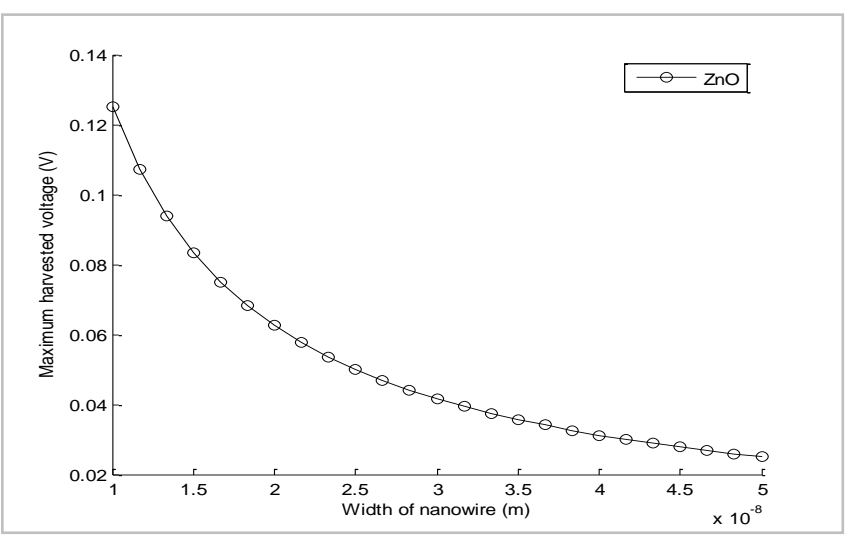

Figure (14): The maximum harvested voltage for rectangular cross section of $\mathrm{ZnO}$ nanowire against width of the nanowire. 


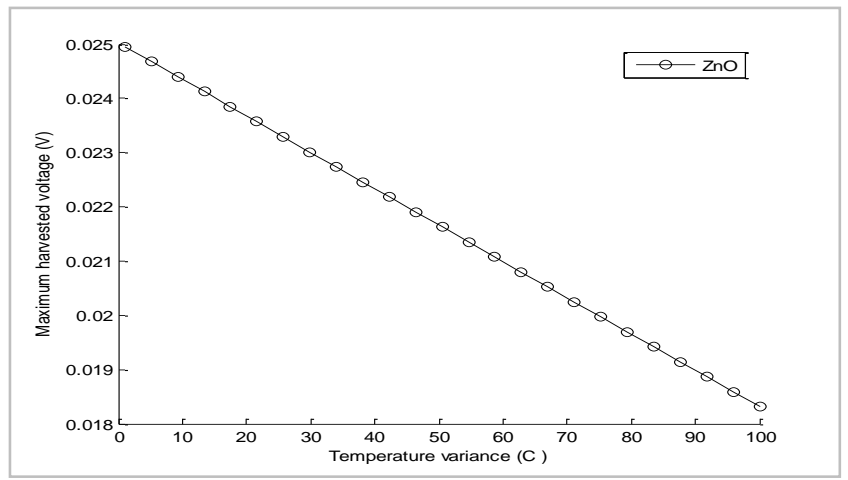

Figure(15): The maximum harvested voltage for rectangular cross section of $\mathrm{ZnO}$ nanowire against temperature variance.

The effect of temperature on the harvested voltage from a bending nanowire by an external force $F_{y}$ is proportional with the term in eqs.(6), (8) that containing the pyroelectric coefficient and the thermoelastic coefficient. The increase in temperature will produce an increase in the dimensions of the nanowire which leads to the reducution of the maximum harvested voltage. In addition to the thermoelastic behavior for the NW, the pyroelectric coefficient play an important role in energy harvesting principle because most of the studied materials having a strong pyroelectric coefficient like 4400 for $\mathrm{BaTiO}_{3}$ and 1800 for PZT (see table (1), (2)). In general most of the parameters that associated with piezoelectric phenomena having a correlative relation with temperature variance due to the materials thermal, mechanical and electrical properties. The results given in this analysis indicates that nanostructures such as those previously mentioned are able to generate enough electric energy to power variance nanosystems. All parameters of the NW such as length, width, and temperature plus the applied force on the nanowire seem to have clear effects on the generated and harvested voltage.

\section{Conclusion}

In summary, we have studied the possibility of electrical energy generation from ( $\mathrm{ZnO}$, BaTiO3,PZT,ZnMgO, GaAlN and GaN) nanowire structure having rectangular and circular cross-section using certain theoretical calculation method. The maximum voltage obtained is enough to power nanosystem such as sensors. the maximum voltage generated seem to be effected by nanowire length, width, and temperature even with applied force to the NW.

\section{References}

1- Z.L.Wang, "Nanogenerators for Self-powered devices and systems", 1st edition, school of materials science and engineering, Georgia institute of technology, Atlanta, USA, 2011.

2- Z. L. Wang, "Self-powered nanosysems", nanotech, scie. Am. , 82-87, 2008.

3- S. Xu, Y. Qin, C. Xu, Y. Wei, R. Yang and Z. L. Wang, "Self-powered nanowire devices", Nat. Nano. , 5, 366, 2010.

4- J. Liu, P. Fei, J. Zhou, R. Tummala and Z. L. Wang, "Toward high-output nanogenerator", Appl. Phys. Lett. , 92, 173105-1, 2008.

5- Z. L. Wang, W. Xudong, S. Jinhui, J. Liu, and Y. Gao, "Piezoelectric nanogenerators for selfpowered nanodevices", IEEE Pervasive Computing, Vol. 7, 49-55, 2010.

6- X. Wang, J. Song, J. Liu and Z. L. Wang, "Directcurrent nanogenerator driven by ultrasonic waves," Science 316, 102-105, 2010.

7- T.S. Heever, "A zinc oxide nanowire pressure sensor" MSc thesis University of Stellenbosch 2010.

8- S. P Timoshenko, and J.N. Goodeir, "Theory of elasticity" 3rd edition, McGraw-Hill book company, 1969.

9- C. Sun, J. Shi and X. Wang, "Fundamental study of mechanical energy harvesting using piezoelectric nanostructures", University of Wisconsin , 2010.

10- T. Lahmer, "Forward and inverse problems in piezoelectricity", $\mathrm{PhD}$ thesis, 2008.

11- K. M. Cheng, "Electrostatic Testing of Simple MEMS Structures", MSc thesis, University of Manitoba, Manitoba Canada, 2006.

12- A. C. Ugural, S. K. Fenster, "Advanced strength and applied elasticity",1985.

13- C.Ying,B.Chena, Z.L.Wang, "Electricity generation based on vertically aligned $\mathrm{PbZr0.2Ti0.803}$ nanowire arrays" ,NanoEnergy, 2009.

14- M. Zgonik, P. Bernasconi, "Dielectric, elastic, piezoelectric, electro-optic, and elasto-optic tensors of BaTioz crystals", Chinese Academy of Sciences, China 1994. 
15- F.P. Beer, J.T. Dewalf, "Mechanics of materials", third edition, McGraw-Hill book Company, 2002.

16- R. S. Li and J. Jiao, "The effects of temperature and aging on young's moduli of Polymeric Based Flexible Substrates", International Journal of Microcircuits and Electronic Packaging, 1063-1674, V.23, N.4, 2000.

17- A. Erturk, D. J. Inman. "Piezoelectric energy harvesting", 1st edition, John Wiley \& Sons, Ltd. 2011.

18- A. E. Ginna, and S. Surresh, "Theory of indentation of piezoelectric Materials", Acta mater. Vol. 47, No. 7, 2153-2164, Acta Metallurgica Inc. 1999.

19- C. Ying, B. Chena, Z. L. Wang, "Electricity generation based on vertically aligned $\mathrm{PbZr0.2Ti0.8O3} \mathrm{nanowire} \mathrm{arrays"} \mathrm{,Nanoenergy}$ institute, 2012.

20- M. Zgonik, P. Bernasconi, "Dielectric, elastic, piezoelectric, electro-optic, and elasto-optic tensors of BaTioz crystals", Chinese Academy of Sciences, China 1994.

21- A. C. Ugural, S. K. Fenster, "Advanced strength and applied elasticity",1985. 